Article

\title{
Trellis and Vine: Weaving Function and Fiction in Videogame Play
}

\section{Christopher Goetz}

Department of Cinematic Arts and the Public Humanities in a Digital World Cluster, University of Iowa, Iowa City, IA 52242, USA; christopher-goetz@uiowa.edu

Received: 1 July 2018; Accepted: 10 August 2018; Published: 17 August 2018

\begin{abstract}
This paper reviews and synthesizes ideas in the philosophy of play and relevant psychology research in order to address videogame medium specificity, with particular focus on the notion of videogame play as simultaneously "rule-bound" and "make-believe." It offers the sustained analogy of "trellis and vine" for provisionally sorting through the tangle (the "mess" or "assemblage") of function and fiction in games.
\end{abstract}

Keywords: gaming; videogames; play; fantasy; psychology

\section{Introduction}

There was a time when, though my path was rough,

This joy within me dallied with distress,

And all misfortunes were but as the stuff

Whence Fancy made me dreams of happiness:

For hope grew round me, like the twining vine,

And fruits, and foliage, not my own, seemed mine.

Samuel Taylor Coleridge (1996)

"Dejection: An Ode"

One day in the late 1990s, during a moment of quiet reverie, Shigeru Miyamoto noticed a line of ants carrying leaves past his patio seat. Watching the workers disappear under tall blades of grass spurred his imagination: what if the ants were people? The story of how Pikmin (2001) was born in a garden is well known (e.g., Whitehead 2013; Collin 2014; LeJacq 2014). It was not the first instance in Nintendo lore of Miyamoto attributing inspiration to unusual sources, such as daydreaming in his bathtub or recollecting the bamboo forests and caves from his childhood in rural Sonobe, Japan. In his story on Pikmin's genesis, Kotaku's Yannick LeJacq observes that Miyamoto is an oddity since it is rare for most game designers to even talk about inspiration for a game: " . . there's a reason the developers at Sledgehammer don't reflect during interviews about sitting in their gardens and suddenly realizing that this was the way they wanted to have players shoot at bad guys." (LeJacq 2014). As a developer of the Call of Duty series (2011-present), Sledgehammer knows well that "[s]hooting at bad guys isn't a new or groundbreaking concept in video games anymore" (LeJacq 2014). Of course, the flipside of Miyamoto's flash-of-genius approach to mapping new game-design terrain is a cool disinterest in the creative endeavors of industry peers: it is avowedly not by refining existing game designs that Miyamoto plots new directions for his creative work. This is just one way, the Kotaku story suggests, that Miyamoto (with Nintendo) is unabashedly out of sync with a risk-averse industry prone to focus-group testing, incremental change, and the careful emulation of past successes.

The question of what inspires a videogame is a big one, whether its answer relies on authorial intent, evokes the relation of one game to another, or raises consideration of how games both influence 
and are influenced by other media, intellectual or artistic pursuits, or even banal, everyday life in the home; unavoidably, the answer also opens onto the even wider concern of how one defines videogames in the first place. ${ }^{1}$ That is, what happens within any game influences how we think of the space between games: what inspires games, how they change over time, and what influences or is influenced by them.

This paper is intended as a way to think about the space between games. However, for that reason, it is also about how one moment of play is bridged with the next and, like Miyamoto, this paper is inspired by the garden. Its extended analogy for thinking about videogame play draws on the relation between a trellis (a carefully patterned structure intended to facilitate the growth of climbing plants) and a vine, which becomes imbricated with such structures in its pursuit of sunlight. Trellis is to game as vine is to play: the trellis is artificial, rigid, inert, mechanically repetitious in structure, and incomplete on its own (deliberately gap-filled); the vine is organic, dynamic, unpredictable, goal-driven, and can be taken to new heights by the support the trellis offers. The vine may, of course, ignore the trellis altogether and shoot its coiled tendrils in any direction-over time, the lianas woven across various structures may grow and thicken, reinforcing the very objects they had once relied on for support. The analogy is useful for speaking to the relation between play inflected with the structure of rules, and play that abandons rules and stretches out with no more "support" than its own free-form creative energy.

In this regard, there are four key permutations of trellis and vine: vines growing without trellis support; empty patches of trellis (where no vine grows); areas where trellis and vine are tightly intertwined and inseparable without the violence of cutting (analysis); and areas where a vine that has already climbed across the full length of the latticework then overshoots the structure in a new direction (having been first carried to places it might not have otherwise reached). Tending to these trellis/vine permutations is perhaps overkill for simply thinking through broad categories like "game" and "play." However, each arrangement is helpful for conceptualizing the relation between rule-bound and make-believe play—or, by extension, for thinking about the relation between a game's structured repetitions (its rules, systems, algorithms, mechanics, and "loops") and its story elements (fictions, themes, settings, characters, and plot events).

The trellis/vine framework serves as a rejoinder to the central argument of Half-Real: Video Games Between Real Rules and Fictional Worlds (2005), namely Jesper Juul's claim that “ . . a video game is a set of rules as well as a fictional world" (Juul 2005, p. 1). Why devote an entire book to advancing such a seemingly non-controversial claim? The full answer requires contextualizing Juul's writing within contemporaneous conversations about videogame medium specificity, which was a heated topic early in game studies. ${ }^{2}$ For introducing the trellis/vine framework, it suffices to focus on how

1 While definitions of games occur throughout this essay, engaging in a sustained manner with the wider question of how the videogame has been historically defined as a medium would exceed the paper's intended scope. I recommend consulting excellent primers for such a review, such as Salen and Zimmerman (2004) foundational book (especially Chapter 7, "Defining Games"), or Stenros' more recent article, "The Game Definition Game" (Stenros 2016).

The range of literature implicated in the question of what inspires a game is also quite vast. Some approaches inherently value some combination of market forces and the authorial intent of a game's developers, such as most journalistic or chronicle-style histories of the medium, as in Kent (2001), Altice (2015). Critical perspectives such as Bogost (2007) also rely on notions of authorial intent, and could be contrasted with approaches that privilege meanings made by players, such as with Galloway (2006) notion of "countergaming" or Henry Jenkins' argument before the United States Congress about the importance of fan communities (Jenkins 1999). Genre analysis often thinks about games relationally (defining and tracking common terms as they recur and change over time). See Clark et al. (2015) and Faisal and Peltoniemi (2015) for two recent and innovative approaches to defining and classifying videogame genres. For examples of work exploring how games both influence and are influenced by other media, see Jenkins (2006) and Murphy (2011). See Parker (2013) for a helpful primer on games influenced by installation art practices, and Apperley (2010) for a helpful introduction to gaming's relation to everyday life.

2 Juul's book represents a meticulous effort at tracking and organizing different ways of conceiving of rules and fictions in videogames. It is positioned as a stopgap for the phenomenon of game scholars talking past one another (failing to agree on the meaning of basic terminology) on the topic of videogame medium specificity (aka, the narratology/ludology debate). Apperley and Jayemane (2012) describe the narratology /ludology debate as being "somewhat unsatisfying on its own terms because discussion often stalled at an inability to agree on basic premises" (Apperley and Jayemane 2012, p. 7). Juul's response to this debate is very much in keeping with a widespread tendency within recent game studies of explicitly 
Juul approaches the formal question of this debate (i.e., whether narrative analysis is appropriate for thinking structurally about videogames).

\section{A Straw Man Tangled in the Garden of Rules and Make-Believe}

In 2005, Jesper Juul reversed his position that "fiction in games is unimportant" for the study of games qua games. His reversal takes aim at Caillois (1961) oft-cited foray into play theory. Caillois first argues that "the sentiment of as if replaces and performs the same function as do rules" and then concludes that "games are not ruled and make-believe. Rather, they are ruled or make-believe" (Caillois 1961, pp. 8, 9; original emphases). Taking Caillois to mean "that rule-based games do not have a make-believe element," Juul contends that such a "division is ... contradicted by most modern board games and video games. Most videogames are ruled and make-believe" (Juul 2005, pp. 12, 13; original emphases). This distinction may seem like a quibble. However, the stakes here are quite high when it comes to how we think of videogame medium specificity (see note 2 above). Without second-guessing Juul's progressive embrace of game fiction, I argue that this reading makes Caillois into a bit of a straw man. In effect, Juul's eagerness to acknowledge the co-presence of both rules and fictions in games flattens an important distinction in Caillois' writing-a distinction I argue is useful for thinking about the relationship between rules and fictions in games.

In the passage Juul cites, Caillois' main example is Chess, a game that clearly combines both rules and elements of make-believe (i.e., a Medieval theme). It is doubtful Caillois would have overlooked Chess' thematic dimension. Nor does Caillois' argument shunt off the representational qualities of Chess. Rather, Caillois works to distinguish two frames of mind or modes of engagement that, by definition, exclude ("replace and [perform] the same function" as) one another. For example, "One easily can conceive of children, in order to imitate adults, blindly manipulating real or imaginary pieces on an imaginary chessboard, and by pleasant example, playing at 'playing chess'" (Caillois 1961, p. 9). If one knew the rules, one could play chess "for real," meaning that the rules of chess are not mimetic of some real-world phenomenon: the game that is created by the rules "is separated from real life where there is no activity that literally corresponds" (p. 8). Caillois' point is that our motives for following and working within rules (as in a game like Chess) are different from the motives involved with engaging in free-form, make-believe play (such as pretending to play Chess). Although one physical object-one board game-could clearly sustain both kinds of play, to speak of rules or make-believe is to speak of two different sorts of play, in turn: thus, his provocation that "games are ruled or make-believe."

If it is accepted that Caillois does not actually mean one game cannot contain both rules and elements of make-believe, then there is not much in Caillois' model that Juul's prohibits, not even the former's problematic hierarchizing of rule-based play above make-believe play. ${ }^{3}$ For Juul, "a videogame is a set of rules as well as a fictional world," and "[t]o play a video game is therefore to interact with real rules while imagining a fictional world" (Juul 2005, p. 1). Caillois does not preclude the possibility of following the rules of chess (playing chess, in his terms, "for real") while, at moments, also playing at some additional game, such as acting out or imagining the chivalry of Medieval combat.

disengaging from what has often been conceived of as a narrow terminological squabble. For instance, Janet Murray argues that "Game studies, like any organized pursuit of knowledge, is not a zero-sum contest, but a multi-dimensional, open-ended puzzle that we are all engaged in cooperatively solving" (Murray 2005, p. 2).

3 One area where I would suggest breaking with Caillois is in the subtle condescension he holds for make-believe play. Caillois' binary implicitly positions the rule-bound play of mature adults ("ludus") above the free-form improvisational play he observes in children, animals, and "primitive" peoples ("paidia"). That these two poles of play tend to fall in line with (and reinforce) the gendered and colonialist ideas strewn throughout Man, Play and Games is problematic, to say the least. Ian Bogost has observed that there is still "an ontological pecking order" (where one part of a game is "more real than another") in the "embrace of syncretism" that Juul and other ludologists have expressed in the past decade (Bogost 2009). This paper's analogy of trellis and vine is meant to maintain a meaningful distinction between rule-bounded and make-believe play without reinforcing this "pecking order." The image of a vine creeping across a trellis does create a contrast of center and periphery, but "periphery" here is less about the margins than the vanguard. 
That play generally represents a special frame of mind unique from the experience of everyday life has been a much-discussed topic in play theory. ${ }^{4}$ Caillois' opposition of rule-based play to make-believe play calls for a further distinction: two separate and somewhat opposed frames of mind that can only with difficulty be said to openly operate in relation with the same element of a game during the same moment of play.

To an extent, Caillois' differentiation seems to be confirmed by literature in clinical psychology that focuses on the role of make-believe play in children's development. On one hand, make-believe and rule-bound play are treated as two distinct modes of engagement; however, on the other hand, shifts between these modes are considered both routine and difficult to track. Singer and Singer (1990) suggest that make-believe is "a commonplace of human thought," adding that "even 'games with rules,' such as the board game 'Monopoly,' often involve additional pretend elements or are the focus of private or shared fantasies well into adult life" (Singer and Singer 1990, p. 42). And Weisberg (2015) emphasizes the difficulty researchers face when attempting to disentangling the two:

[I]t is sometimes difficult to draw sharp lines between episodes of pretend play and other types of play. Are children engaged in rough-and-tumble play just interacting physically, or are they pretending to be superheroes in a fight? Is a child who stacks blocks just manipulating these objects according to their physical properties, or is she pretending to create a fortress? Even though some kind of imaginative or nonliteral quality is necessary for an action to count as pretence, the presence of this quality is not always immediately apparent to an outside observer, as it is part of the child's internal state ... Researchers struggle with such questions of delineation whenever pretend play is studied (Weisberg 2015, p. 250).

Weisberg goes on to say that make-believe "may not occur throughout the entire episode" of play (e.g., superhero fights or block stacking)—instead, it is more likely that "the activity switches back and forth between being physical play and pretend play," even though it is difficult for outside observers to determine which is which at any moment (Weisberg 2015, p. 250).

The difficulty of "drawing sharp lines between episodes of pretend play and other types of play" during observation might seem to support prevailing attitudes in game studies towards formal analysis. This includes Juul's (2005) assumed simultaneity of rules and fictions, as well as Bogost's (2009) proclamation that "videogames are a mess" of different elements not worth making "tidy" by neatly organizing or analyzing separately, and even Taylor's (2009) suggestion that we make sense of games as "assemblages" of "actors ... , concepts, practices, and relations" that are "interwoven in complex ways at particular historical moments" and are inherently resistant to controlled experimentation or direct, ordered analysis (Taylor 2009, p. 332). It is, perhaps, wishful thinking that conversations about videogame medium specificity will cease-and every call for the topic to be "put to rest" seems, in turn, to inspire more scholars to take up the question, even if just to express a position-a position that likely resembles those mentioned in this paragraph. For the psychologists who study symbolic play in the developmental process, however, distinctions between make-believe and other kinds of

4 Play theory that thinks of play as a special frame of mind has been influenced largely by Bateson (1972, p. 178) psychological notion of "metacommunication" (the various ways animals and people signal "this is play," thus changing how communication within that frame is to be interpreted), as well as Goffman (1961) writings about play, which include the notion of "rules of irrelevance," echoing Caillois' and Huizinga's definition of play as a separate space where unique meanings are generated by arbitrary rules and values. That Goffman would emphasize the irrelevance of "whether checkers are played with bottle tops on a piece of squared linoleum, with gold figurines on inlaid marble, or with uniformed men standing on colored flagstones" reflects a wider contemporary philosophical interest in the unique social and psychological values games introduce (Goffman 1961, p. 19). Goffman proposed the term "transformation rules" (p. 27) to account for how aspects of the real world nevertheless enter the game in some form. The interest play theorists hold in the unique contexts games generate has been recently mistaken as an assertion that games are hermetically sealed "magic circles," unrelated to any real-world issues. For a thorough consideration of how the "magic circle" has been maligned in game studies (e.g., Consalvo 2009), see (Stenros 2014). 
play are regularly sought experimentally. Their efforts to conceptualize this distinction are helpful towards the meager end of even temporarily prolonging the need to yield to gaming's complex, unanalyzable "tangle."

If make-believe and rule-bounded play involve distinct and opposed frames of mind, then play, as an action, likely flits from one mode to the other and back again in much the same way behaviorism conceives of two behavioral systems that are incompatible with one another: via the mechanism of inhibition. That is to say that two distinct behavior systems can tend to come into conflict, so that though both are active, the weaker of the two is inhibited from being expressed. ${ }^{5}$ When one such activity is fully engrossing (even flow-like), then the exclusion of other activities would become even more pronounced. ${ }^{6}$ In short, there are behavioral phenomena that cannot be easily explained without conceiving of distinct systems operating episodically.

Are make-believe play and rule-bound play examples of this? For this question, it is helpful that there exists a subfield of psychology investigating behavior motivation called reversal theory, which posits that "deep human values" often "come in opposites," and that since "every value has a contradictory value," it is, therefore, "difficult for an individual or a group to pursue all values at the same time" (Apter 2017, p. 2). Reversal theory sees play as a "metarepresentational" state-akin to Bateson's concept of "metacommunication" (psychological frame $)^{7}$ - where a certain "bipolarity" is stimulating and pleasurable rather than aggravating and stressful. In this sense, reversal theory's application to play seems to suggest that where an option exists between exaggerating or else fusing two opposites, play's preference seems to lie with the former. Kerr (1991) identifies the distinction between the "real" and the "imaginary" as one such reversal pair which, in play's dramatic oscillations, becomes "synergistic" (i.e., distinct but mutually reinforcing) (Kerr 1991, p. 71). Apter and Kerr (1991) identify another pair as mastery and sympathy, where mastery is a state epitomized by "competitive sports" (akin to Caillois' agôn, which focuses on competition and rules), and sympathy is a state epitomized by "aesthetic experience," "exposure ... to works of art," or, one could add, taking pleasure in a game's fictional and aesthetic dimension (Apter and Kerr 1991, pp. 165-66).

Though these examples are helpful for thinking about ruled and make-believe play as episodic poles, the benefit for thinking of them this way perhaps more clearly lies with the question of motivation. ${ }^{8}$ That these two different modes of play might correspond to two distinct motivations for playing would be a valid reason for conceptually distinguishing the two. One approach might note how ruled and make-believe play seem to correspond to the different personality dimensions Lillard et al.

5 As Bowlby (1982) says of behavioral systems, "Any one pattern ... occurs only episodically, the reason being that the activity of one pattern is commonly incompatible with the activity of others" (Bowlby 1982, p. 85). Consider, further, how the axiom that "a rabbit cannot simultaneously graze grass and hide in a burrow," reflects the notion that different behavior systems sometimes "require different sorts of environments" (Manning and Dawkins 2012; Bowlby 1982, p. 85). If a bird on the feeder is nervous about the proximity of human voyeurs, it may become conflicted (between the need to feed and need to seek safety) and then "exhibit most of the behavior of take-off without actually doing so," a sort of compromise known as an "intention movement" (Bowlby 1982, p. 98).

6 For instance, Csikszentmihalyi (1997) research on "flow" describes a mode of intense engagement that saturates a person's attention so fully that other demands for attention (including even basic bodily needs) tend to be suppressed. It is significant that the rubric of flow is often applied to videogames as especially engrossing activities (when optimally, both balancing and maximizing challenge and skills), as opposed to representational media, which Csikszentmihalyi has argued are less stimulating (Csikszentmihalyi 1997, pp. 31, 67).

7 See note 4 above.

8 This paper draws on existing scholarly work in order to map out a conceptual space for thinking about the dynamics of videogame play in a way that extends beyond what has currently been empirically demonstrated. It would be remiss to not mention recent empirical work on player motivation, such as papers by Kahn et al. (2015) or Ratan et al. (2015), both of which build on Yee (2007) paper, "Motivations for Play in Online Games." These studies in the uses and gratifications tradition rely on self-reported survey data, and are useful for identifying distinctly grouped motivation types. However, they are not intended as finely-ground methodologies for identifying the relationship of different frames of mind during any moment of play. In addition, they rely on the assumption that players can accurately identify motivations and reliably parse (in this case) tricky concepts like story, fantasy, conflict, character, challenge, etc. Since story is a prevalent cultural schema for making sense of the world, its use to describe motivations for playing could in effect capture (and obscure) other motivations that are more difficult to describe in words. 
(2011) describe in their research on sociodramatic play and theory of mind: dramatists and patterners. ${ }^{9}$ That distinct personality types display tendencies towards either rule-based or make-believe play hints at the presence of distinct, underlying motivations for each mode.

In fact, Caillois (1961) himself alludes to motivation throughout his book, especially in the chapter on the "The Corruption of Games," which paints the impulses underlying his taxonomy of games in an especially Freudian light. He argues that when games become corrupted (their free spirit and illusion of separateness destroyed), "the tyrannical and compelling psychological attitude that selects one kind of game to play rather than another" is all that would remain (p. 45). This is because games, he argues, "[provide] formal, ideal, limited, and escapist satisfaction" for the "powerful drives" that underlie these "distinctive attitudes" (p. 45). In corruption, each drive corresponds to "a specific perversion which results from the absence of both restraint and protection" the game provides (p. 45). Agôn's self-reliance in play breaks down to the violent assertion of the self in play's corruption ("Now competition is nothing but a law of nature") (p. 46). When mimicry (make-believe) becomes corrupted, a game of pretending to be someone else or imagining a fictional universe lapses into the dissolution of the self. Together, these drives appear to rehearse Freud's famous perversions (sadism and masochism). As is likely clear at this point, the question of player motivation, once again, does lead back to how we define games. ${ }^{10}$ For Caillois, games are mechanisms for channeling powerful drives and different sorts of games (e.g., ruled and make-believe games) connect with different drives. Beyond this point, however, Caillois' argument remains under-developed, mostly implicit.

\section{The Ball is a Mouse, the Thumb is a Breast: "As If" as a Function}

Perhaps the clearest account of psychological motivation in games comes from Gombrich [1963] (1978), who posits that games become "substitutes" for players by picking a "psychological lock" and thereby enabling pleasure to "cross a boundary which is usually regarded as closed and sealed" (Gombrich [1963] 1978, p. 4). Bateman (2011), who has also written about Skinner Box reward schedules in game design, argues that Gombrich's framework is apt for thinking of how videogames effectively hack players by serving a substitutive function related to (or propped upon) some biological need:

For in this sense 'substitutes' reach deep into biological functions that are common to man and animal. The cat runs after the ball as if it were a mouse. The baby sucks its thumb as if it were the breast. In a sense the ball 'represents' a mouse to the cat, the thumb a breast to the baby. But here too 'representation' does not depend on formal similarities, beyond the minimum requirements of function. The ball has nothing in common with the mouse except that it is chasable. The thumb nothing with the breast except that it is suckable. As 'substitutes' they fulfill certain demands of the organism. They are keys which happen to fit into biological locks, or counterfeit coins which make the machine work when dropped into the slot (Gombrich [1963] 1978, p. 4).

As Bateman aptly notes (and directly in relation to questions of videogame medium specificity), Gombrich's substitutes emphasize function over representation. It is extremely interesting to see "as if" (make-believe) return, but not on a representational register. Rather, through imagined psychological needs, it is the function of a substitute object that evokes the thing it stands for. In this sense, when

9 According to Lillard et al., "Dramatists frequently enacted plots involving other people, whereas patterners' play was more object-dependent and tended not to involve social or communicative exchanges"' (Lillard et al. 2011, p. 301).

10 It should be noted that not all definitions of games emphasize motivation. For instance, Suits (1978) defines games as goals reached only by "inefficient means," a notion that appears, at first, to say little of motivation, or what would make one want to play one game of inefficient means over another (Suits 1978, p. 22). Galloway (2006) claim that videogames are "software systems" that share more in common with accounting programs than traditional board games is meant, provocatively, to flaunt a dismissal of motivation. However, Suits' definition may only appear to benefit from the addition of a clearer account of player motivation, or what leads one to adopt a "lusory attitude" (Suits' term for the mindset required to play a game) (Suits 1978, p. 359). This is discussed further below. 
a rule-bounded game is compelling (when players feel intrinsically motivated to play), that game is no longer "for-" or "in itself," as Caillois would say. Instead, the game becomes, once again, and at all points, an "as if" for players who find pleasure centers unlocked by play that has made use of (or referred to) some privileged thing in the world via a logic of function (not resemblance).

Gombrich's distinction between biological substitutes (those meeting the "minimum requirements of function") and fictional representations of imagined satisfaction (e.g., a pictorial representation) seems to reflect one of Vygotsky (1967) paradoxes of play:

... in play [the child] adopts the line of least resistance, i.e., he does what he feels like most because play is connected with pleasure. At the same time he follows the line of greatest resistance, for by subordinating themselves to rules children renounce what they want since subjection to rule and renunciation of spontaneous impulsive action constitute the path to maximum pleasure in play (Vygotsky 1967, pp. 13-14).

Vygotsky reasons that "to observe the rules of the play structure promises much greater pleasure from the game than the gratification of an immediate impulse" (p. 14). This idea more or less tracks Freud's (Freud [1911] 1958) distinction between the "pleasure principle" (a mode of mental functioning akin to seeking the shortest path to pleasure) and the "reality principle," which seeks a greater (and more reliable) sense of satisfaction by temporarily resisting the most direct conclusion. ${ }^{11}$ Gombrich's "psychological lock" implies a circumstance where something real (i.e., functionally evocative and concrete) breaks into the store of pleasure that has been built up by prolonged resistance to this shortest path. Freud's two principles of mental functioning could also be thought in relation to Bernard Suits' definition of games as "inefficient means," helping explain why the shortest path to the goal is unsatisfying and, in Suits' words, rules are "inseparable from ends" (Suits 1978, p. 24). ${ }^{12}$

If rules help pick psychological locks (whether through delay, subordination, or their functional resemblance to something "real"), and if make-believe seems, in turn, relegated to the hallucinatory (direct) path to satisfaction that the reality principle forecloses-then what accounts for the affective power of fictional/representational elements in the player's experience of the game? Though Bateman (2011) associates rules and mechanics with Gombrich's substitute, he nevertheless maintains that fictions strongly influence the pleasure these picked locks release. In his example-Shadow of the Colossus (2005) - rather than conceiving of each colossus as a series of mechanical obstacles, Bateman (2011, p. 190) argues that "[e]mbodying the foe as a beast, a mighty colossus, does affect the emotional experience of victory against it".13 Bateman (2011, p. 190) concludes that though it is possible to "separate out the functional and representational elements" in a game as a kind of academic exercise, "it is not so easy to distinguish between Juul's rules and his fictions-the two are intimately intertwined". The image Bateman depicts is one where fictions seem to stow away on rules or mechanics, the former amplifying the pleasures produced by engagement with the latter. This represents perhaps one small step beyond the familiar twining of the two poles of play as a "mess" or "assemblage."

Bateman has chosen a difficult, tangled-up example in Shadow of the Colossus, where rules and "fictions" seem impossible to separate during play. Indeed, research into the psychology of credulity (Gilbert 1991) suggests that it would be difficult to disbelieve what we see during play's tense moments, even if we wanted to. Our baseline credulity in the face of what we see or hear is amplified during

11 In Freud's (Freud [1911] 1958) theory, this shortest path to pleasure is the one we imagine or hallucinate based on a memory of satisfaction from the past. Freud theorizes that our ability to sense reality around us ("reality testing") relies on this shortest path's first becoming blocked off (along with the associated stores of pleasure), leaving only the arduous, roundabout path to satisfaction, winding through reality. This condition brings us into the world.

12 See note 10 above.

13 Admittedly, Shadow of the Colossus is a fraught example for Bateman to choose, since its emblazonment in game studies academic literature over the past decade is often due precisely to its emotional complexity. For a helpful review and breakdown of the game's effect on people who think about games for a living, I recommend Cole (2015) DiGRA paper, "The Tragedy of Betrayal". 
moments of stress, or "resource depletion."14 Make-believe, as a mode, would clearly predominate if we were to imagine, in Bateman's example, what the colossus' life was like before the player showed up-what it eats, what it dreams about, or other examples of fleshing out the diegesis. We may take pleasure (or pleasurable pain) in summoning such images in accordance with the rules mediating interaction. However, clearly, such rules are subordinated here to the imaginative process. However, Bateman's example of the colossus' massive size (the difficulty of attain visual, let alone spatial control over it) and its autonomy from the player (its apparent patterns of behavior) are not simply "fictions." Rather, they help comprise the colossus as a functional 'substitute' in Gombrich's sense (i.e., one does not make-believe the size, nor the uncanny way the colossus' movements seems to resemble deeply embedded behavioral patterns we have observed in life).

The expression, "the beast is a colossus several stories tall," contains a "dual representation." ${ }^{15} \mathrm{It}$ is both functional and fictional at the same time. However, when thrown into the challenge of scaling and defeating the colossus, it is required to recognize a series of obstacles and spatial puzzles. And the more completely this task occupies attention (mind and body), the more a functional substitute in Gombrich's sense will dominate our engagement. However, this engagement does not fully exclude consideration of the colossus as a fictional being (for whom we are meant to feel remorse), ${ }^{16}$ nor with considering it as an aesthetically charged, polygonal, textured, and procedurally-animated entity. During spatial negotiation, these other means of referring to the objective seem reduced to a kind of linguistic shorthand. They are momentarily in the backseat. However, it is perhaps from here that they do their best work.

\section{Trellis and Vine: Four Moments}

Caillois' opposition of rules to make-believe ought to be extended to videogames in the sense that "rules" (in the broadest sense here as Gombrich's "minimum requirements of function") render concrete,

14 Forget Coleridge's famous adage about needing to suspend disbelief before narrative fiction. Research into how belief functions has found that credulity is the older and more fundamental state, and that reminding oneself of the un-reality of what one sees requires effort. As Gilbert (1991) both argues and carefully substantiates in a review of empirical research into inherent credulity, Spinoza was correct when he postulated "that unacceptance is a secondary psychological act in which the initial accepting that invariably accompanies comprehension is subsequently undone" (Gilbert 1991, p. 108). To understand is to believe. The negation of a proposition (disbelief) is a more complex and difficult operation than belief: it comes later in development and relies on an initial consideration (a belief) that is then negated. This more complex process is capable of being disrupted.

Empirical research shows that when the mind is overwhelmed through stress or distraction, disbelief is disrupted but not belief: "Resource depletion did not cause subjects to believe that affirmed propositions were false, but it did cause them to believe that denied propositions were true" (Gilbert 1991, p. 113). For example, when distracted or under stress, subjects told something like "President Obama was not born in Kenya" would first consider the affirmative (that he was born there) and then struggle and only negate that affirmative proposition with partial success. These findings have been connected with political rhetoric, propaganda, and brainwashing (torture) strategies. However, for the present discussion, one might expect a stressful or difficult videogame to also produce resource depletion.

15 Recent research on "dual representation" - what psychologists call the capacity to see a "symbolic artifact" as "both the concrete entity itself and, at the same time, its abstract relation to its referent" - suggests that "it is generally difficult for young children to have two active representations of a single entity," and that "the concrete features of a symbolic artifact can interfere with young children's ability to notice its relation to what it stands for" (DeLauche 2011, p. 321). This research explores sign-referent relations that break down when the object-as-sign loses its intended connection to its referent because that object is "a highly salient, attractive, interesting object in and of itself," something which "invites direct physical activity" or play and so makes it more difficult "for young children to treat [the object] as standing for something other than itself" (p. 321).

Videogames indeed make matters messier. The question about whether a game's image is functional-mechanical (i.e., it plays a role in a wider system of rules) or else is representational-fictional (i.e., it plays a role in a wider narrative setting or scenario) attends to a perceived schism at the level of signified (i.e., it leaves out the question of the material salience of the signifier itself - the aesthetics of the pixelated image, for instance). Who can really say whether, at any precise moment in play, a player is primarily engaging with an aesthetic and material object (pixels on a screen behaving in a way that stimulates embodied play), a narrative-signified content ("this is a mushroom, like the things I ate for lunch"), or a functional element of a wider mechanical system ("this power-up gives me the ability to break bricks and sustain one unfavorable enemy collision without dying")? Research only suggests that there is some basic competition at work, and our capacity to simultaneously sustain multiple, competing meanings in one object is challenged the more highly "salient" and interesting that object becomes along one of its potential dimensions of meaning.

16 See note 13 above. 
consistent, and reliable what imagination might otherwise only conjure ephemerally. However, the above discussion demonstrates how "make-believe" is perhaps not the best term for thinking about our relation to narrative, fiction, and representation in videogames. What does the concrete and uninterrupted presence of a thing do to one's capacity to imagine it? If functional objects pick biological locks, and our baseline relation to what we encounter in the world is credulity, then make-believe proper would appear to play very little role in our engagement with videogame images we encounter during play. Nevertheless, make-believe is an important part of videogames with diegetic content.

In videogames, systems, rules, and mechanics enter into a kind of dialectic with fictional elements. To borrow the language of reversal theory, the two constitute a "reversal pairing." Their relationship is bipolar and synergistic. Like a vine weaving in and out of gaps in a trellis, there are moments when fleshing out the diegesis (extending its scope beyond what is functionally present) is prominent, and moments when what occupies the foreground of player activity is engaging with a rigidly-structured set of rules, mechanics, and images (whose make-believe element is temporarily subordinated to their concrete immediacy, their presence before us). That an alternation between the two poles can spur player activity (one providing foil and inspiration to the other) is supported by developmental literature on make-believe play. ${ }^{17}$ I propose the metaphor of a trellis and vine to help to conceptually organize these dynamics into four permutations.

\subsection{Vines Growing without Trellis Support}

The first vine/trellis permutation—vines growing without trellis support-stands for autonomous make-believe play: play that has rescinded its dependence on concrete objects in the world. Of course, it is difficult to conceive of make-believe play that draws on no medium for structural support whatsoever. Imaginary play draws on internalized objects: memories of encounters with the material of the doll or action figure, the tone of one's voice, the body's musculature. Even closed eyelids could be said to offer darkness as a kind of support, a stage for creative demonstrations.

Strictly speaking, no videogame play could fall into this category, since the presentation of representational images, sounds and narrative spaces clearly all lend some support to the imagination's winding tendrils. Even rules themselves lend support. Thus, in this first (largely hypothetical) permutation, the image of a vine that coils against its internal structures, or some other medium, but not the structural support-material or ruled —of a videogame.

\subsection{Empty Patches of Trellis (Where No Vine Grows)}

Empty patches of trellis (where no vine grows), would correspond to rules or procedural interactions built into the videogame that aren't tightly connected to play or that deliberately flaunt their resistance to play. In a broad sense, these patches could be conceived of as a potential interaction beyond the reaches of player skill (or taste), such as secret endings, well-hidden "Easter eggs," seldom-accessed game states or, simply, unpopular games. This permutation could also refer to unused code or assets that remain in the software after release. Websites such as The Cutting Room Floor, or YouTube series such as Shesez's Boundary Break videos (2016-present), which hack games in order to reveal "developer techniques or sometimes unused content that's out of the boundaries of a videogame," could

17 Literature on make-believe and rule-bound play describes instances where, in each case, one form of play becomes an "out-of-frame" inspiration for the other. For instance, Singer and Singer (1990) admit that "although the wider reaches of pretending are inevitably constrained by games with rules, it is apparent that some children at least will persist in introducing additional components of imaginativeness into such games," such as with a girl who creatively links situations that emerge in the board game, Clue, with a television show she watched, Murder She Wrote (Singer and Singer 1990, p. 241). They later also identify the possibility that "a spontaneous fantasy game can be organized into a game with rules," such as an observed example of their children inventing a rule-bound game involving catching leaves as they fall from trees (p. 242). Lillard et al. (2011) identify a range of studies that discuss the "social-cognitive skills" that children build both through "in-frame pretending" and "out-of-frame negotiations," the latter of which appear in "an increasing proportion" as children mature (Lillard et al. 2011, p. 300). 
demonstrate the desire to cover or extend play's activity across these unused patches of algorithmic material, and thus negate them as such (Shesez 2018). Play that actively imagines or seeks out these unused spaces (or that realizes the impulse to flesh out and visit them) likely belongs below, in the fourth trellis/vine permutation, and is itself generative of hacking techniques that essentially create a new game (i.e., a new trellis that supports this exploration beyond boundaries).

Looser or more-inclusive definitions of play (and games) will likely oppose the designation of "empty" trellis, as it smacks of the problematic formalist hierarchy from debates over videogame medium specificity. ${ }^{18}$ However, scholars hoping to counter the prevalence of play in videogame analysis would likely embrace this trellis-vine pairing, which can relate to aspects of the game that exceed conventional definitions of play as well as the player's domain of experience altogether. One prominent example is what Galloway (2006) identifies as "nondiegetic machine acts" in his taxonomy of games-a taxonomy both inspired by Caillois, but also meant to eschew play theory (and decenter the human player) in favor of gaming's wider material and technological properties (thus, Galloway's preference for "operator" rather than "player"). In this sense, "empty" trellis could also correspond to the "software systems" (e.g., Quicken or Microsoft Word) that Galloway provocatively identifies as gaming's most closely related kin, where operators interact with systems, but not in a way most would characterize as play.

In fact, any computer-mediated act of designing or programming a videogame (either professionally or as a modder) would seem to exemplify empty patches of trellis, since this work entails using interactive software for materially productive ends. However, I think examples of mods that, even when played, best fit this permutation of trellis and vine are those implicated in Galloway's notion of "countergaming," (following Peter Wollen's theses on countercinema), which involves modifying games for aesthetic or political reasons. "Countergaming" generally opposes the self-contained fictional bubbles of popular entertainment (and, thus, eschews most forms of pleasure-hacking) and, instead, pursues an aesthetic of estrangement, commentary, and truth (Galloway 2006, pp. 109-10).

It must be emphasized that although the notion of "empty trellis" is introduced as an algorithmic system that lacks recognized forms of play, this "lack" is meant to be a productive or even subversive. In the past decade, there has been an eruption of fascinating and creative experimental games that comment upon gaming as a practice and that deliberately frustrate conventional notions of what it means to "play" a game. Prominent examples include games such as Quinn's Depression Quest (2013) or Rohrer's Passage (2007). However, there is a vital movement underway of queer games that explicitly oppose the naturalization of terms like "fun," which are often defined by and for a narrow demographic of white, male players. ${ }^{19}$ Though these games are often, happily, made by diverse independent authors, Ruberg (2015) also extends this queer potential to commercial games, which are designated as "disappointing" (e.g., Atari's E.T., 1982), "annoying," (e.g., Sega's Super Monkey Ball, 2001-2012), "boring," (e.g., Mystique's Custer's Revenge, 1982), "sad," (e.g., Fullbright Company's Gone Home, 2013), or even intentionally hurtful, as in they "communicate negative emotions, like frustration or sadness" (e.g., Cavanagh's Super Hexagon, 2012) (Ruberg 2015, pp. 118-20). In each case, Ruberg embraces the queer failure of an algorithmic latticework that operates outside the bounds of empowering, enabling, intrinsically motivating play.

In this sense, the second moment of empty patches of the trellis takes on the coloring of a queer refusal to facilitate the weaving of normative (and normalizing) play, which, in this case, is characterized by pleasure and experiences of power.

18 See notes 2 and 3 above.

19 The metaphor of an empty trellis - a trellis that does not satisfy cultural expectations about the kinds of (mostly upward) growth it is supposed to facilitate-happily corresponds to recent work of queer theorists and queer videogame scholars who draw productively on notions of failure and stunted growth. Ruberg (2015), for example, discusses the "queer potential" of games that eschew traditional notions of fun. And Ruberg and Shaw (2017) edited volume, Queer Game Studies, offers a helpful introduction to queerness and videogames more generally. 


\subsection{A Vine Closely Woven into the Trellis}

The third permutation - the condition of a vine closely woven into the trellis-corresponds to a mode of play tightly wound up with the terms of a game's structural support to such an extent that it presents a tangle of prolonged activity (during which it is difficult to conceptually disentangle play and game). Further, though the game's support is mechanical and procedural (images and actions that are rule-bound or "functional"), it can also be conceived of as representational, fictional, and (kin)aesthetic. That is, both ruled and make-believe play (or "mastery" and "sympathy" play) can predominate at particular moments (inhibit without completely banishing their counterpart). In this metaphor, the vine's twining does really rely on the game's mechanical supports, the domain of rules and systems, what Bateman calls gaming's "grip and grind" (Bateman 2011, p. 31). This is in reference to reward schedules and the process of building skills over time (in short, where the game most clearly serves as a Gombrich substitute, a key for a "biological lock"). Yet, when focused, prolonged play reverberates (such as the "Tetris effect"), the memory often features internalized aesthetic or representational imagery and sounds, which, in this permutation, have become inseparable from the rules governing their interaction. The pleasure "unlocked" during play has fused the circuits and bridged disparate metarepresentational polarities.

Play generated through negotiation of the videogame's rules becomes an intense nexus of player energy and attention over long periods of time. ${ }^{20}$ As they work through a game's reliably repetitious processes, players become stitched into the game's algorithmic loops, and the game's strange rhythms become embedded as muscle memory. As new aspects of the game's system are revealed, skills and abilities expand in a rhetoric of growth and progress, which appears to speak as much to player as avatar. However, to a regular gamer, growth also characterizes gaming itself, which in each new game (we hope, at least) seems to push marginally outward towards new interactive terrain.

In the third permutation, the non-differentiation of this embedding into muscle memory of rules and procedures, as well as fictions and representations is reflected in simple linguistic utterances—and, to be clear, this happens in "standard" input schemas, as well as dance and exercise games. To say that the sun is setting in a game like Super Mario World 2: Yoshi's Island (1995) speaks perhaps narrowly to the game's fictional backdrop, so that contemplating this notion may pull players across the clear boundary that separates foreground and background as well as the domain of gameplay from that of the game's fictional setting. However, to say the same thing during Minecraft (2011) is unavoidably to encounter a more precarious dual representation that includes, on one hand, a fictional backdrop (i.e., there is no actual "sun" in Minecraft, just a fictional representation of one), as well as, on the other hand, a cluster of significant rules structuring the action of play-rules about what is visible and what is not, how and where monsters spawn, and whether players should explore or retreat. The fictional term ("sun") serves as a kind of linguistic short-hand for the full range of rules instantiating Gombrich's substitute objects. Our access to fictional shorthand likely works constantly in the background to stitch together and lend coherence to a game's virtual spaces and encounters as play winds around the trellis. While Gombrich's substitute functions, as affective intensities swell, even bizarre and

20 Nicoll (2015) essay on the Neo Geo and the domestication of arcade games notes that, when games entered the home, their address to players shifted, including their relationship with duration:

Rather than focusing on the blunt thrills and excessive spectacles of arcade gaming, home video games now aspired to provide long-term appeal with their engrossing stories and intellectually stimulating-but not punishing or overly challenging-gameplay. Magazine review criteria were even adjusted to factor in the longevity of a game, often quantified under a "value" or "replay-value" rubric. This also coincides with a time when games adhered less to established arcade genres and became more multifaceted and innovative in terms of their gameplay mechanics and modes of presentation. (Nicoll 2015, p. 215). 
arbitrary fictional elements (sounds, gestures, appearances, actions) take on a quality of necessity and immediacy, moving from "as if" to "as is." 21

In short, the third permutation is gaming's mainstay, both conceptually and commercially—what distinguishes videogames from other sorts of software and from other representational arts, as well as what underlies the "grip and grind" that fuels gaming as an industry. However, it is also in this third permutation that I would include most mods, hacks, speedruns, and exploit-seeking. To be precise, modifying an existing game (or building a new one out of existing code and assets), like game design more generally, is a process that stretches across multiple trellis/vine permutations. It expresses the twining of trellis and vine insofar as the creative process-the meticulous, iterative, nature of designing and programming-combines a nuanced consideration of a game's structural support with the play that defines it as support. A vine has grown in the programmer's mind, so to speak, leading to an intense focus of some sort that stitches together a pleasurable oscillation between code and its execution. This stitching action is discussed further in the final section.

Exploit-seeking could be understood as an effort to locate and activate overlooked or as-yet poorly understood aspects of the trellis and to fold them back into play (to grow a vine there too). In a related vein, speedrunning could be understood as combining the pursuit of exploits (exceptional vine grown in overlooked places) with the meticulous drawing of the trellis into the self as "structural support" (i.e., muscle memory) until the near approximation of perfection is achieved and recorded (a vine absolutely inseparable from trellis-perhaps actualized in machine-assisted speedrunning). Notably, exploit- or glitch-seeking and speedrunning both eschew gaming's representational contents and fixate to the point of a productive obsession with game rules or processes. Further, for these practices, it is unimportant whether play is sanctioned by designers, or else clearly exceeds expected boundaries for play-in both cases, the trellis itself (as it comes to be understood) serves a powerful author function, even as one's understanding of it grows and transforms over time.

\subsection{A Vine, Having Climbed Across the Entirety of the Latticework, Overshoots the Structure in a New Direction}

Finally, the fourth permutation, areas where a vine, having climbed across the entirety of the latticework, overshoots the structure in a new direction, corresponds with a kind of make-believe play inspired at the point rules no longer combine with (and support) play's creative action. Rules still may play a background role, since the creative energy that extends play beyond the trellis' formal "limits" is often built upon many hours of activity stabilized and held in view by that trellis. When make-believe play that has been strongly imprinted by rules stretches out autonomously in a new direction, it seems to long for new support that would capture and sustain its imagined actions. In other words, it seeks out something familiar in its imagining of something new. Like a vine coiling back upon itself, its growth may seem inefficient. However, unlike the hypothetical coiling tendril in the first permutation, this autonomous vine is explicitly imagined as having a particular kind of momentum - it has been drawn across the familiar paths of a videogame's structural support, and because of this it appears to call for a modification of the trellis itself.

One way to think of this fourth permutation is that make-believe play that overshoots the trellis tends to predict and precede genre development in terms of gameplay. Edge-of-trellis is a kind of ludic vanguard. How does an industry track the vine's overgrowth and respond? Whether by focus groups or sparks of genius, the "vine" is clearly also a vein (lifeblood) for industry profits. Player-made mods are hailed, perhaps, for their greater autonomy and lower overhead-in other words, for their flexible cobbling together, fixing, and rapid extension of an existing trellis infrastructure in response to momentary creative offshoots. Perhaps the boundaries of a game's algorithmic support often, in practice, take the form of a narrative fiction that launches a make-believe impulse beyond the trellis'

21 See note 14 above. 
frame. In short, if it cannot be directly programmed yet, then at least it can be captured in narrative; as an invisible wall, it gestures to something beyond.

A teleology emerges: decades of narrative cinema and television about daring escapes into space vessels (e.g., Star Wars: The Empire Strikes Back, 1980), precede punctuated moments during bookended cutscenes in popular videogames where a protagonist must return to a space ship and flee an exploding planet (e.g., Super Metroid, 1994), which in turn precede a new genre of games where the passage into and out of the space craft is a seamless, fluid, and regular part of play (e.g., StarMade, 2012; No Man's $S k y, 2016)$. A narrative fiction built beyond the outer limit of a sidescroller's trellis of play (Samus' ship that waits for her at game's end) finds, in a new genre we might call Minecraft in space, a new trellis to support such dramas of venturing from, and returning to, the vessel's protective hull.

It should be noted that many games actively seek out this fourth permutation, the outer boundary of the trellis, but not in order to imagine its future extension. Or, put otherwise, they are deliberately sparse in their trellis. Prominent examples include industry-produced games featuring quick-time-events or build-your-own-adventure narratives. During these games' interactive cutscenes, a trellis of play has been reduced to the literal presentation of a button on the screen, and mechanics simply include pressing that button, or not pressing that button. A perhaps more significant example would be independently produced narrative games, such as those created on Twine (e.g., Quings Quest VII: The Death of Videogames!, 2014). A minimalist structural support is intended, in these games, to spur make-believe play and then to get out of the way. The vine overshooting the trellis is, here, precisely the point of play during play, rather than a commercially-driven connective fiber between game iterations.

What the fourth permutation perhaps illuminates about the relationship between rules and make-believe is that rules seem to unburden imagination, to extend its reach, to offload the labor of imagining by pulling that work into the body as a whole (into the nervous system, body schema, muscle memory) by way of the body's role in testing reality, knowing its world implicitly. Though present in significant ways during play that focuses on rules (the dual representation of the vine wound around the trellis), make-believe is often second-fiddle, most clearly present as a valence, backdrop, or linguistic shorthand for play's action. As with a reversal pair that has neglected one of its poles, make-believe play returns with gusto at moments when the trellis falters or fails. Or, perhaps, when imagination wanders away from the game and to unexpected places.

Funding: This research received no external funding.

Conflicts of Interest: The author declares no conflict of interest.

\section{References}

Altice, Nathan. 2015. I Am Error: The Nintendo Family Computer/Entertainment System Platform. Cambridge: MIT Press.

Apperley, Thomas. 2010. Gaming Rhythms: Play and Counterplay from the Situated to the Global. Amsterdam: Institute of Network Cultures.

Apperley, Thomas, and Darshana Jayemane. 2012. Game Studies' Material Turn. Westminster Papers in Communication and Culture 9: 5-25. [CrossRef]

Apter, Michael. 2017. Ideology and Societal Values: A Reversal Theory Perspective. Journal of Motivation, Emotion, and Personality 6: 1-7.

Apter, Michael, and John Kerr. 1991. The Nature, Function and Value of Play. In Adult Play: A Reversal Theory Approach. Edited by John Kerr and Michael Apter. Leiden: Swets \& Zeitlinger, pp. 163-76.

Bateman, Chris. 2011. Imaginary Games. Alresford: John Hunt Publishing.

Bateson, Gregory. 1972. Steps to an Ecology of Mind. New York: Ballantine Books.

Bogost, Ian. 2007. Persuasive Games. Cambridge: MIT Press.

Bogost, Ian. 2009. Videogames are a Mess. DiGRA Keynote. Available online: http://bogost.com/writing/ videogames_are_a_mess/(accessed on 15 May 2018).

Bowlby, John. 1982. Attachment and Loss: Volume 1: Attachment, 2nd ed. New York: Basic Books. 
Caillois, Roger. 1961. Man, Play, and Games. Translated by Meyer Barash. London: University of Illinois Press.

Clark, Rachel, Jin Ha Lee, and Neils Clark. 2015. Why Video Game Genres Fail: A Classificatory Analysis. Games and Culture 12: 445-65. [CrossRef]

Cole, Tom. 2015. The Tragedy of Betrayal: How the design of Ico and Shadow of the Colossus elicits emotion. Paper presented at 2015 DiGRA International Conference, Lüneburg, Germany, May 14-17.

Coleridge, Samuel Taylor. 1996. Dejection: An Ode. In English Romantic Poetry: An Anthology, Dover Thrift ed. Edited by Stanley Appelbaum. Mineola: Dover Publications.

Collin, Robbie. 2014. Nintendo's Shigeru Miyamoto: 'What Can Games Learn from Film? Nothing. The Telegraph. November 10. Available online: https://www.telegraph.co.uk/culture/film/film-news/11201171/ nintendo-super-mario-pikmin-tokyo-film-festival-mandarin-oriental-tokyo-sega-mario-kart-zelda-wiioculus-rift.html (accessed on 21 May 2018).

Consalvo, Mia. 2009. There is no magic circle. Games and Culture 4: 408-17. [CrossRef]

Csikszentmihalyi, Mihaly. 1997. Finding Flow: The Psychology of Engagement with Everyday Life. New York: Basic Books.

DeLauche, Judy. 2011. Early Development of the Understanding and Use of Symbolic Artifacts. In The Wiley-Blackwell Handbook of Childhood Cognitive Development, 2nd ed. Edited by Usha Goswami. Hoboken: Wiley-Blackwell.

Faisal, Ali, and Mirva Peltoniemi. 2015. Establishing Video Game Genres Using Data-Driven Modeling and Product Databases. Games and Culture 13: 20-43. [CrossRef]

Freud, S. 1958. Formulations on the Two Principles of Mental Functioning, stand. ed. London: Hogarth Press, vol. 12, pp. 213-26. First published 1911.

Galloway, Alexander. 2006. Gaming: Essays on Algorithmic Culture. Minneapolis: University of Minnesota Press.

Gilbert, Daniel. 1991. How Mental Systems Believe. American Psychologist 46: 107-19. [CrossRef]

Goffman, Erving. 1961. Encounters: Two Studies in the Sociology of Interaction. London: Penguin University Press.

Gombrich, Ernst. 1978. Meditations on A Hobby Horse. London: Phaidon Press. First published 1963.

Jenkins, Henry. 1999. Congressional Testimony on Media Violence. Available online: http://web.mit.edu/m-i-t/ articles/dc.html (accessed on 17 June 2018).

Jenkins, Henry. 2006. Convergence Culture: Where Old and New Media Collide. New York: New York University Press. Juul, Jesper. 2005. Half-Real: Video Games between Real Rules and Fictional Worlds. Cambridge: MIT Press.

Kahn, Adam, Cuihua Shen, Li Lu, Rabindra Ratan, Sean Coary, Jinghui Hou, Jingbo Meng, Joseph Osborn, and Dmitri Williams. 2015. The Trojan Player Typology: A Cross-Genre, Cross-Cultural, Behaviorally Validated Scale of Video Game Play Motivations. Computers in Human Behavior 49: 354-61. [CrossRef]

Kent, Steven. 2001. The Ultimate History of Video Games. New York: Three Rivers Press.

Kerr, John. 1991. 'A Structural-Phenomenology of Play' In Context. In Adult Play: A Reversal Theory Approach. Edited by John Kerr and Michael Apter. Leiden: Swets \& Zeitlinger, pp. 31-42.

LeJacq, Yannick. 2014. Pikmin Has the Best Origin Story. Kotaku. Available online: https:/ /kotaku.com/pikminhas-the-best-origin-story-1657571859 (accessed on 21 May 2018).

Lillard, Angeline, Ashley Pinkham, and Eric Smith. 2011. Pretend Play and Cognitive Development. In The Wiley-Blackwell Handbook of Childhood Cognitive Development, 2nd ed. Edited by Usha Goswami. Hoboken: Wiley-Blackwell.

Manning, Aubrey, and Marian Dawkins. 2012. An Introduction to Animal Behavior, 6th ed. Cambridge: Cambridge University Press.

Murphy, Sheila. 2011. How Television Invented New Media. New Brunswick: Rutgers University Press.

Murray, Janet. 2005. The Last Word on Ludology v. Narratology. Paper presented at DiGRA “Worlds in Play" Conference, Vancouver, BC, Canada, June 16-20.

Nicoll, Benjamin. 2015. Bridging the Gap: The Neo Geo, the Media Imaginary, and the Domestication of Arcade Games. Games and Culture 12: 200-21. [CrossRef]

Parker, Felan. 2013. An art world for artgames. Loading ... 7: 41-60.

Ratan, Rabindra, Nicholas Taylor, Jameson Hogan, Tracy Kennedy, and Dmitri Williams. 2015. Stand by Your Man: An Examination of Gender Disparity in League of Legends. Games and Culture 10: 438-62. [CrossRef]

Ruberg, Bonnie. 2015. No Fun: The Queer Potential of Video Games that Annoy, Anger, Disappoint, Sadden, and Hurt. QED: A Journal in GLBTQ Worldmaking 2: 108-24. [CrossRef] 
Ruberg, Bonnie, and Adrienne Shaw. 2017. Queer Game Studies. Edited by Bonnie Ruberg and Adrienne Shaw. Minneapolis: University of Minnesota Press.

Salen, Katie, and Eric Zimmerman. 2004. Rules of Play: Game Design Fundamentals. Cambridge: MIT Press.

Singer, Dorothy, and Jerome Singer. 1990. The House of Make-Believe: Children's Play and the Developing Imagination. Cambridge: Harvard University Press.

Stenros, Jaakko. 2014. In defense of a magic circle: The social, mental and cultural boundaries of play. Transactions of the Digital Games Research Association. p. 2. Available online: http://todigra.org/index.php/todigra/ article/view /10/26 (accessed on 10 June 2018).

Stenros, Jaakko. 2016. The Game Definition Game: A Review. Games and Culture 12: 499-520. [CrossRef]

Suits, Bernard. 1978. The Grasshopper: Games, Life and Utopia. Peterborough: Broadview Press.

Taylor, T. L. 2009. The Assemblages of Play. Games and Culture 4: 331-39. [CrossRef]

Vygotsky, Lev. 1967. Play and its Role in the Mental Development of the Child. Soviet Psychology 5: 6-18. [CrossRef] Weisberg, Deena Skolnick. 2015. Pretend Play. Wiley Interdisciplinary Reviews: Cognitive Science 6: $249-61$. [CrossRef] [PubMed]

Whitehead, Thomas. 2013. Feature: A Brief History of Pikmin. NintendoLife. Available online: http://www. nintendolife.com/news/2013/07/feature_a_brief_history_of_pikmin (accessed on 21 May 2018).

Yee, Nick. 2007. Motivations for Play in Online Games. CyberPsychology E Behavior 9: 772-75.

Shesez. 2018. Boundary Break. Available online: https://www.youtube.com/playlist?list=PLYfhW_PMkU7vBmWwwyqdIWNDzXfEZwnO (accessed on 28 June 2018).

(C) 2018 by the author. Licensee MDPI, Basel, Switzerland. This article is an open access article distributed under the terms and conditions of the Creative Commons Attribution (CC BY) license (http://creativecommons.org/licenses/by/4.0/). 